\title{
Geo-spatial approach-based landslide susceptibility mapping using analytical hierarchical process, frequency ratio, logistic regression and their ensemble methods
}

\author{
Anik Saha ${ }^{1} \cdot$ Sujit Mandal ${ }^{2} \cdot$ Sunil Saha ${ }^{1}$
}

Received: 7 November 2019 / Accepted: 27 August 2020 / Published online: 9 September 2020

C) Springer Nature Switzerland AG 2020

\begin{abstract}
Kurseong municipality and its surrounding hill slope are famous high altitudinal residential areas in the Darjeeling Himalayan region of India. In Darjeeling Himalayas, huge landslides occur in the rainy season every year. This paper was aimed to delineate landslide susceptibility zone (LSZ) in Kurseong and its surrounding hill slope in Darjeeling Himalayas. Nine landslide inducing parameters (i.e., slope, altitude, rainfall, geological structure, distance from river channels, distance from lineament, soil type or characteristics, land-use/land-cover and aspect) were used for mapping LSZ applying analytic hierarchy process (AHP), frequency ratio (FR), binary logistic regression (BLR) models and their ensemble (AHP-FR; AHP-BLR; and FR-BLR) with the aid of ArcGIS, SPSS and ERDAS software. The landslide susceptible maps produced in GIS environment by the AHP, FR, BLR and their ensemble models were classified into five susceptibility classes such as very low, low, moderate, high and very high. The area under curve (AUC) of receiver operating characteristics (ROC) and kappa statistics were used to analyze the accuracy of the LSZ maps. The AUC values of prepared maps were $78.86 \%$ (AHP), 80.22\% (FR), 80.67\% (BLR), 83.44\% (AHP-FR), 84.39\% (AHP-BLR) and 84.73\% (FR-BLR). Overall kappa statistics were 0.789 (AHP), 0.812 (FR), 0.799 (BLR), 0.837 (AHP-FR), 0856 (AHP-BLR) and 0.868 (FR-BLR), indicating the good accuracy of the models. The mapping of LSZ will be useful for land-use planning and future landslide hazard mitigation strategies.
\end{abstract}

Keywords Analytic hierarchy process · Frequency ratio - Binary logistic regression · Ensemble modeling · Landslide susceptibility mapping $\cdot$ Kurseong region

\section{Introduction}

The most distressing environmental hazards in the Himalayan mountainous and adjacent foot-hill area are landslide. The landslide (LS) causes damage to human life, assets and infrastructure in the Himalayan mountain region [1, 2]. Landslide is a complex process, which is caused due to some internal and external factors. The inherent factors consist of the stability situation of the slope, geological factors, soil category, groundwater condition, geometry of slope (slope inclination, aspect, elevation and curvature) and land-use/land-cover changes [3-6]. Several researchers developed specific models or approaches to map the landslide susceptibility zone (LSZ) in numerous mountains areas around the world. Analysis of LSZ includes consideration of the physical factors that cause slope instability in an area, assessment of their contribution and appraisal of their aggregate influence. This is carried out using a variety of methodologies that can be widely categorized as qualitative and quantitative analyzes, considering the physical factors identified as variables causing landslides. Basharat and Saha offered a detailed description of the analysis

$\triangle$ Sunil Saha, sunilgeo.88@gmail.com; Anik Saha, aniksahamalda@gmail.com; Sujit Mandal, mandalsujit2009@gmail.com | ${ }^{1}$ Department of Geography, University of Gour Banga, Malda, West Bengal, India. ${ }^{2}$ Department of Geography, Diamond Harbour Woman's University, Diamond Harbour, West Bengal, India. 
of those techniques $[4,5]$. The qualitative methodology uses specific parameters focused on subjective judgment rules taken by the geoscientist on the landslide-influencing physical factors $[4,7]$. In addition to the recently introduced approaches, such as the fuzzy technique, they include statistical and geotechnical methods $[7,8]$.

The probability of LS was investigated in the mountainous area of several countries, like Japan, Korean, Bhutan, Malaysia, India, etc. $[5,9,10]$. Sakkas applied a generalized model of the linear combination process for analyzing LS susceptibility in Greece [11]. The slope failure probability models and logistic regression models were applied for LS risk assessment [12]. Raghuvanshi [13] described that the internal parameters handle the stable status of the shield, such as geological factors (lithological structure, soil type and underground conditions), shield geometry (shield aspect, curvature or height) and also land-use/ land-cover. The machine language-based artificial neural network model for LSZ analysis was applied in the Cameron, Malaysia [14]. Saaty [15] initiated the analytical hierarchy process (AHP), the semiquantitative method based on comparative judgment. AHP method was subsequently applied in Taiwan and Nepal for LSZ mapping [16, 17]. Soil characteristics were used for slope mass rating and modeling the landslide susceptibility in Himalayan mountainous area [18]. The LSZ mapping was done in Inje area basin of Korea using logistic regression [19]. Saha et al. analysis [5] and Shit et al. analysis [20] applied the probabilistic approaches for the LSZ risk and hazard analysis. Ensemble model for LSZ mapping using RS and GIS was applied by Basharat et al. [4], Park et al. [19] and Nithya et al. [21]. The risk of LS and its vulnerability in the European mountainous region were deliberated using various models used in different researcher's work $[9,10]$. Some notable LS modeling works have been done using the hybrid methods [22], explicit deep learning neural network model [23], artificial neural network model $[24,25]$, adaptive neuro-fuzzy inference system (ANFIS) multiple meta-heuristic model [27].

Sarkar et al. [27] in their work assigned numeric weight to the landslide-conditioning factors on the basis of occurrence of landslide in the study area. In the AHP model, weights are allocated to landslide-conditioning factors for predicting the landslide probability. Recently, some researches were done to prepare the LSZ map using AHP method in the Himalayan region [4, 5, 20]. A large number of researchers produced LSZ maps using frequency ratio (FR) and binary logistic regression (BLR) models [5, 28-30]. The relationship between LS site and landslideconditioning factors can be analyzed through the BLR model [30-32].

The Kurseong and its surrounding area are regularly hit by the landslides and trigger tremendous losses of life and property. Mapping the landslide susceptibility zones is important for handling landslide problems in this area. The main objective of this paper is to prepare the LSZ maps of Kurseong municipal and it surrounding in Darjeeling Himalaya using individual AHP, FR, BLR methods and their ensemble models. The comparison of the efficiency of novel ensemble AHP-FR, AHP-BLR and FR-BLR methods with performance of individual $A H P, F R$ and BLR models in landslide susceptibility assessment is the main novelty of this work. The ensemble technique of AHP-FR, AHP-BLR and FR-BLR methods is yet not implemented in landslide susceptibility studies in Darjeeling Himalayan, India. The key advantage of the study is that an accurate landslide susceptibility map (LSM) was being developed, which is a crucial asset for land and town planners in the mountainous area. These maps will assist the planner to adopt the mitigation strategies and to allocate suitable areas especially for the development of infrastructure activities.

\section{Materials and methods}

\subsection{Study area}

Kurseong municipality along with its neighboring downhill slope of Darjeeling Himalaya is extended between $26^{\circ} 46^{\prime} 30^{\prime \prime}$ and $26^{\circ} 57^{\prime} 47^{\prime \prime}$ North latitudes and $88^{\circ} 08^{\prime} 25^{\prime \prime}$ to $88^{\circ} 27^{\prime} 54^{\prime \prime}$ longitudes comprising an area of $380.33 \mathrm{~km}^{2}$ in the district of Darjeeling, WB, India (Fig. 1). Municipality of Kurseong is a subdivisional town and a hill station. The name 'Kurseong' is come from the word 'Kharsang,' originally a local word 'Lepcha,' connoting 'the land of white orchids' [33].

It is one of the most ancient urban centers. Kurseong Town was founded back in 1835 when the British Government of India brought this region out of the kingship of Sikkim. The tiny hamlet eventually became a popular spot for the colonial government in 1880 and became a favored location for sanatoriums where the ill would heal. It has a nice year-round climate, and winters are not as extreme as they were in Darjeeling. The region's climate is aligned with climate-type CWA (subtropical humid) by Koppen. The average annual temperature is $23.69{ }^{\circ} \mathrm{C}$, and the average annual rainfall is about $325 \mathrm{~cm}$ (weather record for the municipalities from 1991 to 2016). During the north-east monsoon, the marked rainy seasons are observed in the first week of June to the last week of September [5]. Through the northeast monsoon, it receives rainfall during both northeast monsoons. Every year, Monsoon (June-September) rainfall induces a number of landslides and destroys property and farmland. It is observed that the spatial distribution of landslides in the region is influenced by both morphological and hydrological characteristics of the 

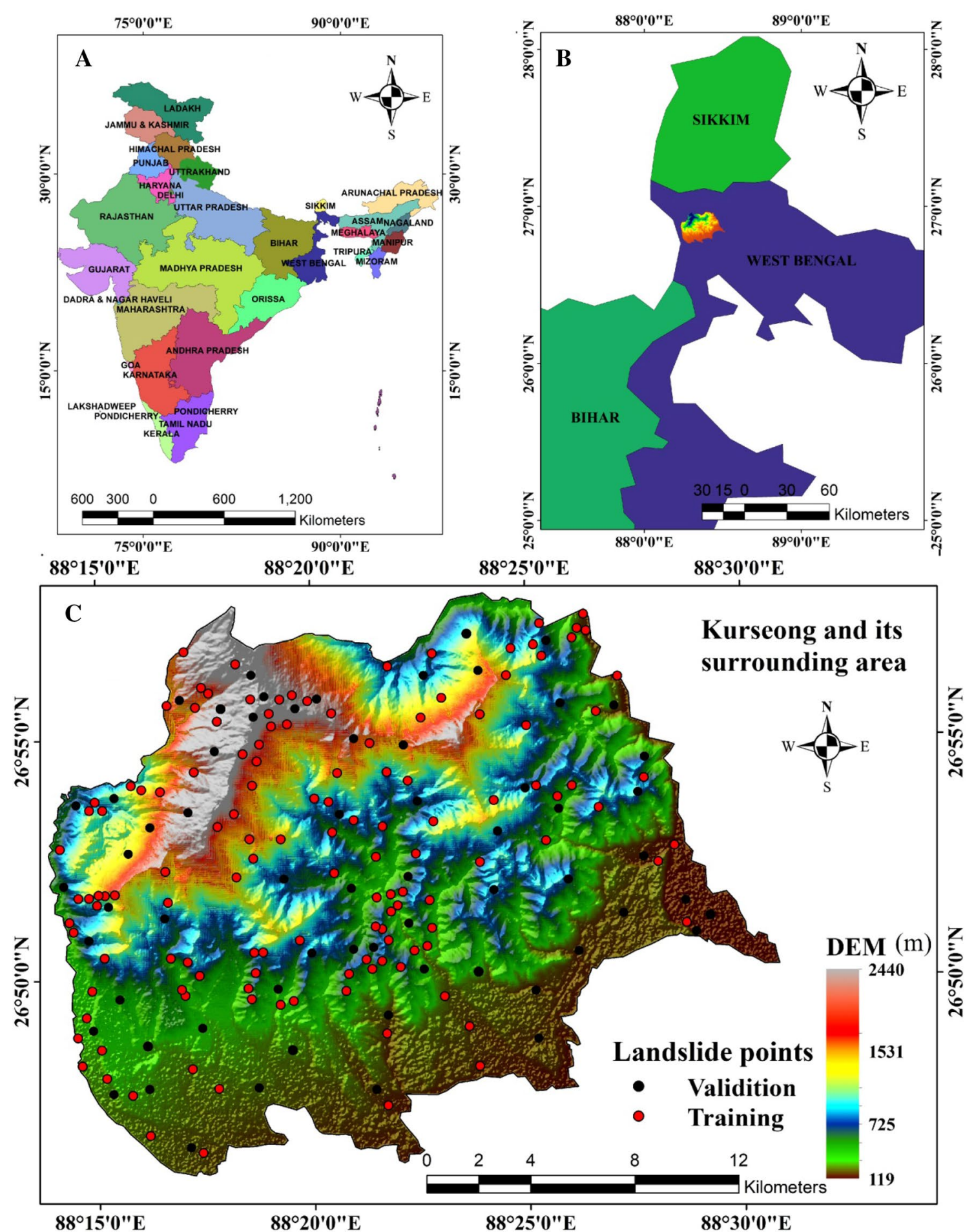

Fig. 1 Location map of the study area: a India, b Northern part of West Bengal, c Kurseong and its surrounding area with landslide points

slopes. The region portrays a heavily sculpted degraded environment in its youthful stage of turbulence cutting down by tumultuous streams and rivers coupled with preexisting geological deformities with rocks of Darjeeling gneiss and Daling sequence of Archaeans, Permian 
Gondwana rocks, Siwalik rocks and Pleistocene elevated terrace (Geological Survey of India) [34].

\subsection{Database}

The Landsat $8 \mathrm{OLI}$ satellite imageries (30-m resolution) of 2018 were used to derive land-use data and Google Earth imageries were utilized to identify landslides in Kurseong and its surroundings. Nine contributing factors such as (a) altitude, (b) slope, (c) aspect, (d) rainfall map, (e) drainage system, (f) lithology, (g) land-use/land-cover (LULC), (h) lineament and (i) geology related to the occurrence of landslides were considered to prepare LSZ map in Kurseong and its nearby region of Darjeeling Himalaya. The aspect, slope and altitude map were derived from the Shuttle Rader Topography Mission (SRTM)-based DEM (created by NASA), using ArcGIS 10.3 platform (Table 1). In addition, these maps were classified using the quintile method $[35,36]$. Geological map was derived from GSI, soil zonation map from NBSS and LUP Regional Centre, lineaments driven from bhuvan.nrsc.gov.in website and drainage system driven from Toposheet (Table 1). The LULC was generated from Landsat 8 OLI (Bands 2, 3 and 4; resolution $30 \mathrm{~m}$ ) data using supervised classification technique and maximum likelihood algorithm through ERDAS 14.0 software. Field visits were carried out to realize the ground truth of landslide inventory. The process of preparing landslide susceptibility maps followed a number steps which are explained one by one (Fig. 2).

\subsection{Landslide inventory mapping:}

According to Balzano et al. [2], Roy et al. [28], Zhao et al. [31], the first and foremost move for the assessing of an area's landslide susceptibility is to examine, locate and map the landslides. This may be achieved by field surveys or via highresolution aerial imagery. The LS occurrences were identified and mapped by field inspection and with the help of high-resolution imagery from Google Earth for the current study. The LS occurrences were identified and mapped by field inspection and with the help of high-resolution imagery from Google Earth for the current study. In general, spatial mapping of landslides is required to assess the relationship between distributions of $L S$ with the predisposing factors of the LS. At first, LS locations were recognized using the GPS coordination system, and later, the location of LS was drawn as a polygon using Google Earth images (Fig. 3). A total of 221 LSs locations are identified in this study area. Within 221 cases, $70 \%$ are being applied as training data to accumulate $\mathrm{LSI}$, and the remaining $30 \%$ is applied to authenticate those models [37-39]. Hence, it was found out that LSs are most common in the middle and steep slope base upper altitude of this study area. In the lower part of the study area, the landslides were found along riverside, and they occur almost every year. Many landslides in the upper catchment are mainly restricted to under-gravity scrambling of rocks and rubble. The landslides are mostly debris, topsoil and mud flow in the middle catchment area, but in the western part of the middle catchment, rock falls sometimes happen as well.

\subsection{Susceptibility modeling techniques}

\subsubsection{Analytic hierarchy process (AHP) analysis}

AHP is an important multi-criteria decision approach (MCDA) which is used for assigning the weights. The AHP is a technique which calculates throughout pairwise comparisons of dissimilar factors. Based on expert decisions, the priority scales put on [39]. According Saaty, the comparison can be done using a nine-point scale or real data [39]. The 9-point weight extent includes: $[9,8,7,6,5, \ldots 1 / 5$, $1 / 6,1 / 7,1 / 8,1 / 9]$, where 9 means extreme preference, 7 means very active preference, 5 means strong preference, and so on, low to 1 , which means no preference (Table 2) $[40,41]$. The procedure is to assign priority weights for every factor through computation of normalized eigenvector (EV) which is very popular method of measuring the preferences from inconsistent pairwise comparison matrices [40]. The weights were derived by summing up the values in each column of pairwise comparison matrix,
Table 1 Various data layer with source used in the study

\begin{tabular}{lll}
\hline Major data & Sources & Scale or resolution \\
\hline $\begin{array}{l}\text { Topographical map and } \\
\text { Google Earth (2018) }\end{array}$ & $\begin{array}{c}\text { Survey of India (SOI), Kolkata. Map no. 78B/5 and } \\
\text { Google earth }\end{array}$ & $1: 50,000$ \\
$\begin{array}{l}\text { Geological map } \\
\text { Leological Survey of India (GSI), Kolkata }\end{array}$ & $1: 250,000$ \\
$\begin{array}{l}\text { Landsat 8 (OLI) (Path 139; } \\
\text { Row 41) }\end{array}$ & Earthexplore.usgs.gov (date-29/02/2018) & $1: 50,000$ \\
SRTM DEM & Earthexplorer.usgs.gov (date-23/09/2014) & $30 \mathrm{~m} \times 30 \mathrm{~m}$ \\
Soil map & NBSS and LUP Regional Centre, Kolkata & $30 \times 30 \mathrm{~m}$ \\
World climate data & https://www.worldweatheronline.com/lang/en-in/ & 3 os $\left(\sim 1 \mathrm{~km}^{2}\right)$ \\
& west-bengal.aspx & \\
\hline
\end{tabular}


Fig. 2 Flowchart of methodology

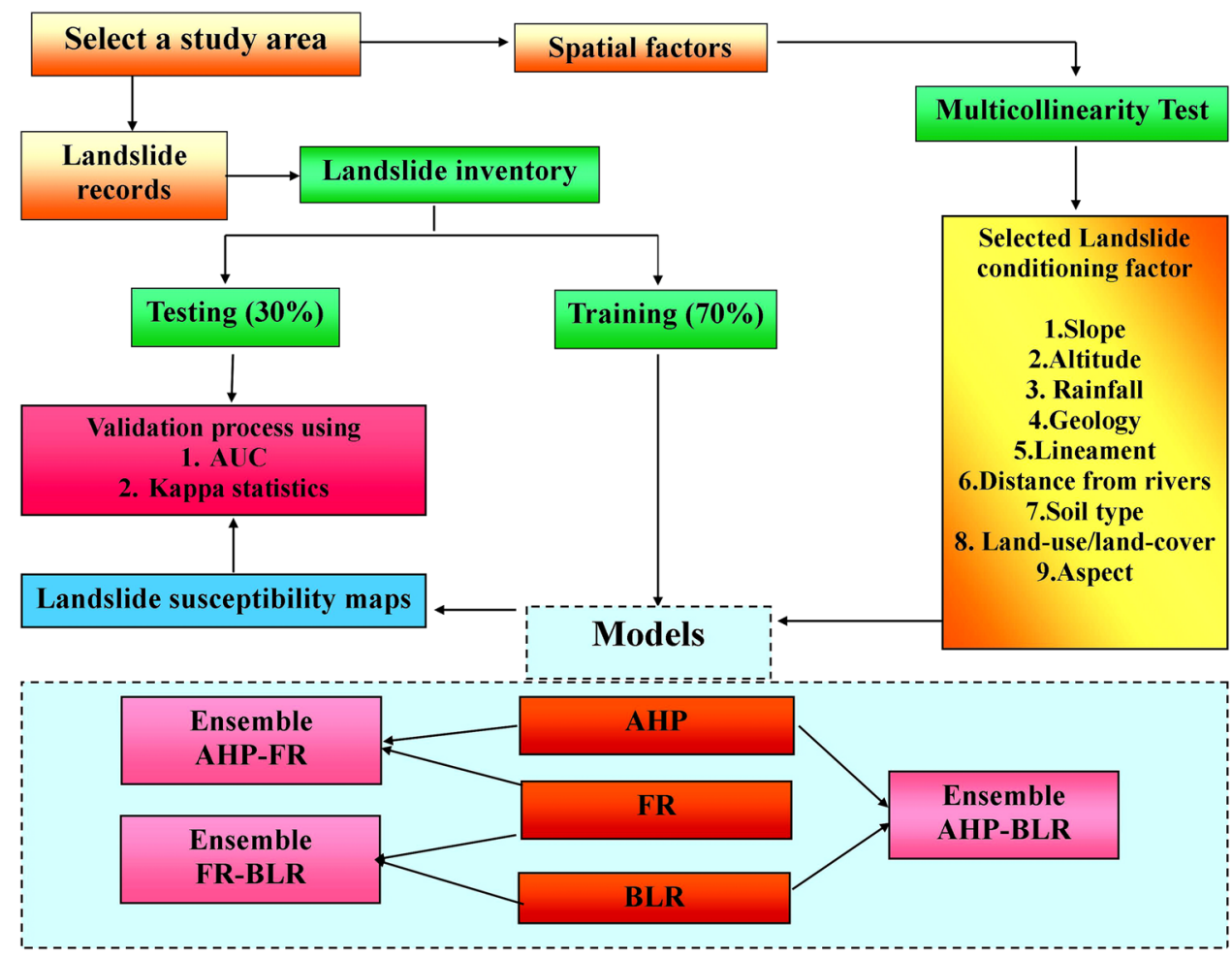

and each cell value is divided by the summed values of the same factors column. The average value of each row is the primary eigenvector of the matrix. As this matrix was randomly prepared, for this reason, some degrees of inconsistency may occur $[17,41]$. The calculation table arranges in the tabular format according to Saner technique [42]. pixels in the subclass of landslide-conditioning factor; and ' $t x$ ' is the total pixels $[43,45,46]$.

The FR value is indicating the association of landslide occurrence and landslide-conditioning variable. The landslide susceptibility index (LSI) was calculated by summing up of Fr values of every factor using the ArcGIS raster calculator in Eq. 2.

$\mathrm{LSI}=\left(\begin{array}{l}\text { slope classesfr }+ \text { Altitudefr }+ \text { Geological structurefr }+ \text { Distance } \\ \text { from lineament fr }+ \text { Distance from riverfr }+ \text { Soilfr }+ \text { LULCfr }+ \text { Aspectfr }\end{array}\right)$

\subsubsection{Frequency ratio (FR) model}

FR defines the proportion of landslide pixels for each input layer in the specific category [43-45]. FR assumes that future landslides will occur in conditions similar to the past. It may be defined as the ratio of landslide pixels in a category (a class of factor) to the relative frequency of all landslide pixels in an area. FR values for subclass of every factor were calculated using Eq. (1).

$\mathrm{FR}=\frac{f / t f}{x / t x}$

where ' $f$ ' is landslide pixels in the subclass of landslide conditioning; ' $t f$ is the total landslide pixels; ' $x$ ' is the total
(LSI: landslide susceptibility index; fr: the rating of each factor's class). The landslide susceptibility map was prepared using the $\mathbf{L S I}$ values and is shown in Fig. 5b.

\subsubsection{Binary logistic regression (BLR) model}

Logistic regression (LR) is a statistical model that allows for the evaluation of multivariable regression between a dependent and a group of independent variables [9, $29,31]$. The major benefit of logistic regression is that it can perform with the help of an appropriate link function to the ordinary linear regression. In this case, if the data are either continuous or categorical, or both, there is no problem and the regression does not require the normal distribution of data. For this analysis, the binary number ' 0 ' denotes non-landslide points and the binary number ' 1 ' denotes landslide point. The logistic regression method 

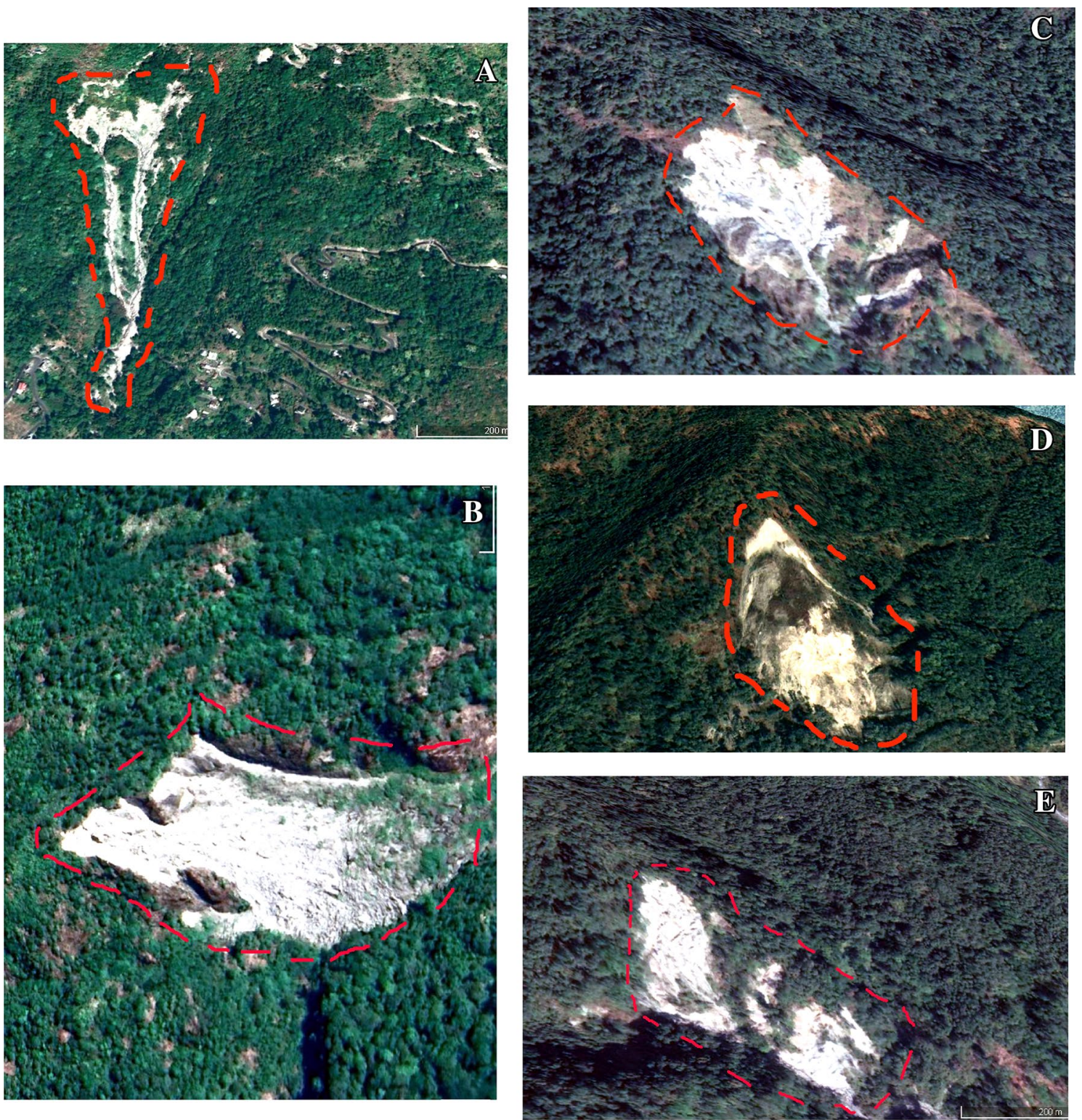

Fig. 3 Some landslide Google images collected through Google earth pro a $26^{\circ} 55^{\prime} 01^{\prime \prime} \mathrm{N}$; $88^{\circ} 19^{\prime} 28^{\prime \prime} \mathrm{E}$; b $26^{\circ} 52^{\prime} 23^{\prime \prime} \mathrm{N}$; $88^{\circ} 21^{\prime} 01^{\prime \prime} \mathrm{E}$; c $26^{\circ} 52^{\prime} 37^{\prime \prime} \mathrm{N} ; 88^{\circ} 2^{\prime} 26^{\prime \prime} \mathrm{E} ; \mathbf{d} 26^{\circ} 55^{\prime} 42^{\prime \prime} \mathrm{N} ; 88^{\circ} 26^{\prime} 31^{\prime \prime} \mathrm{E}$; and e $26^{\circ} 53^{\prime} 09^{\prime \prime} \mathrm{N} ; 88^{\circ} 27^{\prime} 07^{\prime \prime} \mathrm{E}$ in this study area

means optimum likelihood calculation after the translation of the dependent variable into the logit component. Thus, logistic regression measures the probability of an event.

In this BLR model, the calculation was done applying Eqs. 3 and 4 and more detail can be found in some recently published articles [29, 30]. BLR model can be carried out using Eq. 3

$$
L S^{p}=\frac{1}{\left(1+A f^{-z}\right)}
$$

where 'LS ${ }^{p \prime}$ denotes the landslide probability. 'Af' denotes the affecting factors selected in this work. 'LSI' denotes the liner model combination, and it ranges between $-\omega$ and $+\omega$ (Eq. 4).

$\mathrm{LS}=\left(a_{0}+a_{1} x v_{1}+a_{2} x v_{2} \ldots a_{n} x v_{n}\right)$

where' $a_{0}$ ' signifies models intercept. The ' $a_{1}, a_{2} \ldots a_{n}$ ' signify the slope of coefficient. And the $x v_{1}, x v_{2}, \ldots, x v_{n}$ denotes the independence factor number. 


$$
\begin{aligned}
\mathrm{LSI}= & \text { Intercept }-(\text { Slope } * B)+(\text { Altitude } * B)+(\text { Rainfall } * B)+(\text { Distance from lineament }) \\
& +(\text { Distance from Drainage } * B)+\text { Geology } B+\text { Soiltype } B+\text { Land }- \text { cover } B+\text { Aspect } B
\end{aligned}
$$

where $B$ is the logistic regression coefficient value, while land-use/land-use $B$, geology $B$, soil type $B$ and aspect $B$ are the logistic regression coefficient values.

Based on independent variables, the BLR model forecasts the existence or absence of LS. On the basis of prefailure conditions (independent variables), the linear LR represents the existing conditions (presence or absence of landslide). For the landslide susceptibility mapping by the BLR first, all the pixels of map were converted into points and then used these as input data layers in the SPSS software to calculate logistic regression values [47]. The logistic regression model is considered as quantitative method that finds out the effects of individual independent variable with the help of the coefficients and antilogarithm of the coefficients $[9,30]$. Finally, the BLR model-based LSZ map was prepared using Eq. 5 [29, 30, 47, 48].

\subsection{Process of models' ensemble}

The ensemble modeling is a technique of joining the effects of different models into an incorporated embedded model to develop predictive capability $[35,48-50]$. This technique has risen in recent last few years of reducing gully erosion [35]; modeling flood probability [49]; landslides susceptibility [50]; and different purposes. In this work, the ensemble models can be generated using the weighted combination of an individual model. The ensemble technique of AHP-FR, AHP-BLR and FR-BLR has been followed by sequentially khosravi [49], althuwaynee [50] and Shafapour Tehrany [51] articles.

\subsection{Landslide-influencing factors:}

Major nine LS-influencing factors, those are the altitude, slope, rainfall map, slope aspect, soil map, geomorphology, distance from lineaments, distance from rivers and LU/LC map, were prepared to generate LSZ map. The landslide-conditioning factors are selected based on the literature survey and multi-collinearity test.

\subsubsection{Slope}

Slope having great role in making the area susceptible to landslide is frequently used in preparing LSZ maps $[32,38$, $52,53]$. For this research, the slope map was prepared from DEM and classified into six groups (Fig. 4a).

\subsubsection{Altitude}

Altitude is a frequently used parameter for landslide susceptibility assessment $[30,48,52]$. In the study, the elevation ranges between 120 and $2440 \mathrm{~m}$ and is classified into 5 categories (Fig. 4b). To prepare this LSZ map, the elevation was divided into 5 groups and their weights were estimated according to matrix and consistency ratio for each class.

\begin{tabular}{|c|c|c|}
\hline $\begin{array}{l}\text { Important } \\
\text { concentra- } \\
\text { tion }\end{array}$ & Classification & Explanation \\
\hline 1 & Equal importance & Two activities contribute equally to the objective \\
\hline 3 & Weak importance of one over another & $\begin{array}{l}\text { Experience and judgment slightly favor one activity over } \\
\text { another }\end{array}$ \\
\hline 5 & Necessary or strong importance & $\begin{array}{l}\text { Experience and judgment strongly favor one activity over } \\
\text { another }\end{array}$ \\
\hline 7 & Demonstrated importance & $\begin{array}{l}\text { An activity is strongly favored, and its dominance is demon- } \\
\text { strated in practice }\end{array}$ \\
\hline 9 & Supreme importance & $\begin{array}{l}\text { The evidence favoring one activity over another is of the } \\
\text { highest possible order of affirmation }\end{array}$ \\
\hline $2,4,6,8$ & Intermediate values between the two adjacent judgments & When compromise is needed \\
\hline $\begin{array}{l}\text { Reciprocals } \\
\text { of more } \\
\text { than } \\
\text { nonzero }\end{array}$ & $\begin{array}{l}\text { If activity I have one of the above nonzero numbers assigned } \\
\text { to it when compared with activity } j \text {, then } j \text { has the reciprocal } \\
\text { value when compared with } i\end{array}$ & \\
\hline
\end{tabular}

Table 2 The comparison scale in AHP (Saaty 1990) 
Fig. 4 Landslide-conditioning factors: a slope, b altitude, c rainfall, $\mathbf{d}$ geological structure, e distance from lineament, $\mathbf{f}$ distance from river, $\mathbf{g}$ soil map, h land-use/land-cover map and $\mathbf{i}$ aspect map
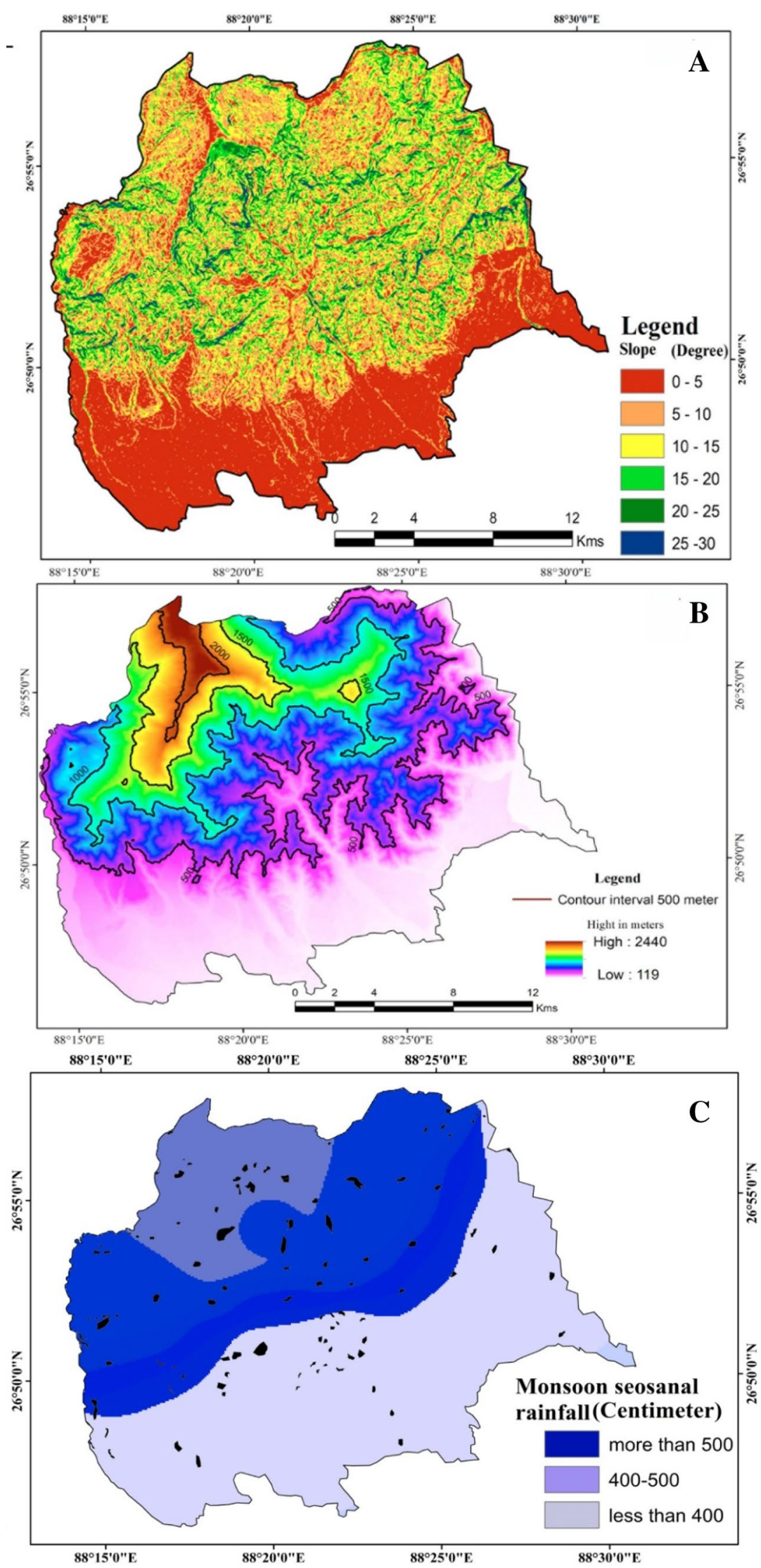

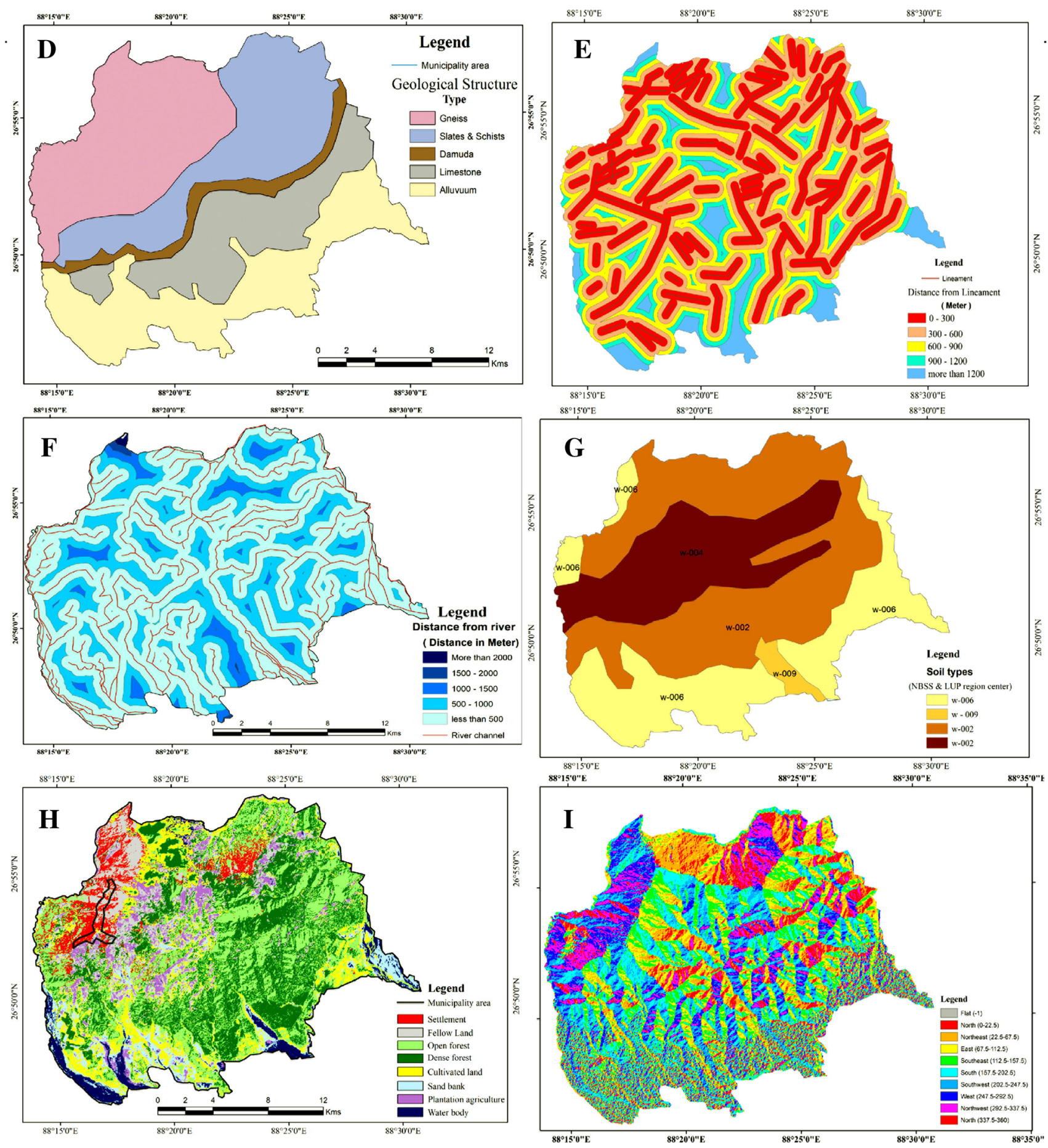

Fig. 4 (continued)

\subsubsection{Rainfall}

The role of antecedent rainfall in causing landslides is also investigated by considering daily rainfall during failure and the cumulative rainfall to discover at what point antecedent rainfall plays an important role in Himalayan landslide processes $[43,44]$. Rainfall is an essential trigging factor in landslide occurrences [17]. In the Himalayan region, mean precipitation is very high compared to another part of India. The average is $525.5 \mathrm{~cm}$ in June, 
July, August and September month of the monsoon season (https://www.worldweatheronline.com/lang/ en-in/west-bengal.aspx). In the study, the average monsoon rainfall map was generated and divided into three classes, i.e., $400 \mathrm{~cm}, 400-500 \mathrm{~cm}$ and more than $500 \mathrm{~cm}$ per monsoon season (Fig. 4c).

\subsubsection{Geological}

The geomorphological element is the most notable phenomenon which plays an important role in landslides [55]. The high peak in the study area appears in the north-western part. This Himalayan part is regarded as the structural mountains, denudation plain and floodplain. Geological map of the study area was collected from the Geological Survey of India (GSI). The boundaries of geological segment and names of the geological unit were used in previous studies $[34,43,55,56]$. This region is dissected into numerous small ridges, spurs, deep' $V$ '-shaped valleys and other erosional features. The geological map was digitized using ArcGIS v10.3 software and was converted into a grid map with $30 \mathrm{~m} \times 30 \mathrm{~m}$ resolution. Alluvium and limestone deposits have a high capability for water adsorption and influence the landslide occurrences. Gneiss and States-Schist are semipermeable and have a limited water adsorption potential, and this geological unit is moderately susceptible to the landslide.

\subsubsection{Lineament}

Faults form a weak line or zone well marked by broken rocks $[28,31,34,43]$. The lineament map was derived from bhuvan.nrsc.gov.in with a 1:50,000 scale. The distance from lineaments was calculated by Euclidean distance buffer tool in GIS environment and classified into 5 categories considering an interval of $300 \mathrm{~m}$ (Fig. 4e).

\subsubsection{Distance from the river}

Another important, promising and functional variable is the distance from the river for landslide occurrences [43, $45,47]$. Howard (1997) notified that isolation is a limited model, which influences the dominant hills-shield transportation process in relation to distance from the river and mean decay rates, through a threshold presence or absence for landslides and climate corrosion $[55,56]$. The distance from the river was divided into 5 categories where an interval of $500 \mathrm{~m}$ was taken into account [36, 55-60] (Fig. 4f).

\subsubsection{Soil type}

The soil of Eastern-Himalayan hill and foot-hill area depends upon the fundamental geological structure [14, 34]. But, in general, the soil has been formed in cooperation fluvial action with lithological disintegration (Fig. 4g). The soils formed in the Kurseong area are predominantly reddish in color. Occasional dark soil is found due to the extensive existence of Phyletic and schist. Soils in the highland stretching from the west to east of the district along most of the inter-fluvial areas are mainly a mixture of sandy loam and loamy, and southern slopes of Kurseong are mainly composed of clayey loam and reddish in color. The basic soil types of the study area are yellow soils, redbrown soils and forest soils. Main soil types of the study area are WOO2 (Course Loamy, Typic Udorthents, Loamyskeletal, Typic Dystrochrepts), WOO4 (Loamy-skeletal, Typic Udorthents, Loamy-skeletal, Typic Haplumbbrepts), WOO6 (Course loamy, Umbric Dystrochrets) and W0O9 (Fine Loamy, Umbric Dystrochrepts, Course Loamy, Typic Udorthents). In the Kurseong, due to the presence of gneiss rock the red-brown soil and red soils are developed. In some parts of the study area, dark clayey soils are also present.

\subsubsection{Land-use and land-cover}

Rapid settlement expansion (building) takes place on mountain slopes where large landslides occurred historically that are not realistically sustainable in this area [34, $46,60,61]$. This could result in major loss of property and human life at the time of future high magnitude landslide. In Kurseong hilly regions, land-use patterns are an important influencing factor for landslide occurrence [5]. Some restrictions should be imposed on building constructions for sustainable environmental management in Kurseong and its surrounding Darjeeling Himalaya [33, 34]. The forest and pasture areas should not be used for various purposes, which is announced by the Darjeeling hills area development program under the 8 th 5 -year plan. The major land-use is tea gardens where landslides are being observed noticeably. In addition, deep forest, plantation and riverside lands are also susceptible to landslides where the expansion of human settlement happened. The Sentinal-2 data were derived from glovis.usgs.gov satellite at $10 \mathrm{~m}$ scale (using band 2; band 3; and band 4). The West Bengal government blockwise LULC map, the topographical map from SOI no. 78B/5 and field verifications were incorporated and processed through ArcGIS v10.3 and 
Table 3 Classification accuracies of LULC

\begin{tabular}{lllll}
\hline Class name & \multicolumn{4}{l}{ LULC from Landsat 8 OLI satellite data } \\
\cline { 2 - 5 } & Reference & Classified & Correct & $\begin{array}{l}\text { Condi- } \\
\text { tional } \\
\text { kappa }\end{array}$ \\
\hline Settlement & 40 & 40 & 36 & 0.895 \\
Plantation & 30 & 25 & 23 & 0.914 \\
Social forestry & 24 & 21 & 21 & 1.000 \\
Open forest & 29 & 24 & 22 & 0.910 \\
Deep Forest & 33 & 32 & 27 & 0.831 \\
crops zone & 56 & 50 & 44 & 0.872 \\
Sand Deposition & 16 & 19 & 16 & 0.844 \\
Water Body & 20 & 20 & 18 & 0.895 \\
Total & 248 & 231 & 207 & \\
& Kappa statistic 0.872 & & \\
\hline
\end{tabular}

ERDAS v14 software (Table 1) for preparing the LULC map of the study area. Thereafter, this LULC map was converted into a grid map with a resolution of $30 \times 30 \mathrm{~m}$ (Fig. 4h). The accuracy of the LULC map was assessed by applying kappa statistics. Overall classification kappa statistics is 0.8727 , which is desirable (Table 3).

Table 4 Result of multi-collinearity diagnosis of landslide conditioning factors

\begin{tabular}{lll}
\hline Independent variables & TOL & VIF \\
\hline Slope & 0.596 & 1.945 \\
Altitude & 0.745 & 1.308 \\
Rainfall & 0.445 & 2.648 \\
Geological structure & 0.529 & 1.854 \\
Distance from lineament & 0.584 & 1.873 \\
Distance from river & 0.737 & 1.269 \\
Soil types & 0.784 & 1.284 \\
Land-use/Land-cover & 0.774 & 1.257 \\
Aspect & 0.791 & 1.146 \\
\hline
\end{tabular}

\subsubsection{Aspect}

The slope aspect was recognized as a driving factor for a landslide $[17,34,59]$. The aspect map was derived from the digital elevation model (Fig. 4i). Due to an increase in moisture during the rainy season (July-September), some parts in the south-east and the south-western part of this Himalayan range become much more vulnerable to landslide occurrences.

\section{Results}

\subsection{Multi collinearity test}

Before preparing the landslide susceptibility models by the AHP, FR and BLR testing of multi-collinearity among the independent variables is essential $[36,56,60,61]$. A tolerance of less than 0.10 and/or a VIF of 5 and above indicates a multi-collinearity problem [62-64]. In this study, both indices were calculated (Table 4). The values of tolerances and VIF of all the selected parameters are more than 0.2 and $<10 \%[62,64]$. So, there is no collinearity problem among the selected landslide determining factors. Among these selected factors rainfall factor has the highest VIF (2.648) and the slope aspect has the lowest VIF value (1.146).

\subsection{Landslide susceptibility maps}

In the calculation of AHP highest consistency ratio (CR) is achieved by slope (0.137) and lowest by aspect (0.033). Rainfall (0.092), altitude (0.112), distance from river (0.059) and geological structure (0.076) are also have high CR value (Table 5). In FR model the weight of soil type w-004 (16.22) is the highest and $83 \%$ of landslides are found in this soil segment. FR model also depicting that soil type w-006 (3.57) settlement (1.25) and fellow land (0.95) are highly influencing factors for LS and the opposite situation found in slope 0 to $5^{\circ}(0.19)$, dense forest (0.63); open
Table 5 Pairwise comparisons, factors priority and consistency ratio by AHP

\begin{tabular}{lllllllllll}
\hline Factors & Slope & Altitude & Rainfall & Geology & DL & DR & Soil type & LU LC & Aspect & Weight $\left(W_{i}\right)$ \\
\hline Slope & 1 & 2 & 3 & 3 & 4 & 5 & 6 & 8 & 9 & 0.129 \\
Altitude & $1 / 2$ & 1 & 2 & 2 & 3 & 4 & 5 & 8 & 9 & 0.113 \\
Rainfall & $1 / 3$ & $1 / 2$ & 1 & 2 & 2 & 3 & 4 & 5 & 7 & 0.087 \\
Geology & $1 / 3$ & $1 / 2$ & $1 / 2$ & 1 & 2 & 3 & 4 & 5 & 5 & 0.075 \\
DL & $1 / 4$ & $1 / 3$ & $1 / 2$ & $1 / 2$ & 1 & 2 & 2 & 3 & 5 & 0.059 \\
DR & $1 / 5$ & $1 / 5$ & $1 / 4$ & $1 / 3$ & $1 / 2$ & 1 & 2 & 2 & 3 & 0.051 \\
Soil type & $1 / 7$ & $1 / 5$ & $1 / 5$ & $1 / 3$ & $1 / 3$ & $1 / 2$ & 1 & 2 & 3 & 0.045 \\
LULC & $1 / 8$ & $1 / 7$ & $1 / 5$ & $1 / 5$ & $1 / 3$ & $1 / 3$ & $1 / 2$ & 1 & 2 & 0.038 \\
Aspect & $1 / 9$ & $1 / 7$ & $1 / 7$ & $1 / 5$ & $1 / 5$ & $1 / 3$ & $1 / 3$ & $1 / 2$ & 1 & 0.033 \\
\hline
\end{tabular}


Table 6 Pairwise comparison matrix for consistency ratio; weights of each sub layer by AHP method and frequency ratio (FR) values of the landslide-conditioning factors

\begin{tabular}{|c|c|c|c|c|c|c|}
\hline \multirow[t]{2}{*}{ Main factor (layer sequence no.) } & \multirow[t]{2}{*}{ Subclass } & \multicolumn{2}{|c|}{ AHP method } & \multicolumn{3}{|c|}{ FR values of the landslide conditioning } \\
\hline & & $\begin{array}{l}\text { Consist- } \\
\text { ency Ratio } \\
\text { (CR) }\end{array}$ & Priority $\left(R_{i}\right)$ & $\begin{array}{l}\text { Number of } \\
\text { pixel in sub- } \\
\text { class }\end{array}$ & $\begin{array}{l}\text { Number of pixel } \\
\text { under landslide }\end{array}$ & Frequency ratio \\
\hline \multirow[t]{6}{*}{ 1. Slope $\left({ }^{\circ}\right)$} & $0-5$ & 0.127 & 0.022 & 152,237 & 1922 & 0.19 \\
\hline & $5-10$ & & 0.027 & 105,763 & 1308 & 0.81 \\
\hline & $10-15$ & & 0.036 & 118,334 & 2111 & 0.56 \\
\hline & $15-20$ & & 0.037 & 59,348 & 1524 & 0.40 \\
\hline & $20-25$ & & 0.055 & 21,954 & 1045 & 0.21 \\
\hline & $25<$ & & 0.112 & 8539 & 678 & 0.12 \\
\hline \multirow[t]{5}{*}{ 2. Altitude (m) } & $2000<$ & 0.109 & 0.182 & 32,632 & 1631 & 0.25 \\
\hline & $1500-2000$ & & 0.091 & 51,279 & 3006 & 2.17 \\
\hline & $1000-1500$ & & 0.045 & 88,573 & 3349 & 1.26 \\
\hline & $500-1000$ & & 0.023 & 181,809 & 1249 & 1.35 \\
\hline & $500>$ & & 0.015 & 163,161 & 686 & 1.67 \\
\hline \multirow[t]{3}{*}{ 3. Rainfall (cm) } & $500<$ & 0.092 & 0.219 & 181,709 & 4559 & 0.39 \\
\hline & $500-400$ & & 0.147 & 46,616 & 691 & 0.67 \\
\hline & $400>$ & & 0.074 & 237,849 & 3326 & 0.69 \\
\hline \multirow[t]{5}{*}{ 4. Geological structure } & Alluvial & 0.076 & 0.021 & 111,882 & 1975 & 0.57 \\
\hline & Gneiss & & 0.032 & 125,867 & 2490 & 0.51 \\
\hline & States-schist & & 0.129 & 97,896 & 1892 & 0.51 \\
\hline & Limestone & & 0.146 & 107,220 & 1803 & 0.59 \\
\hline & Damuda & & 0.193 & 23,310 & 428 & 0.54 \\
\hline \multirow[t]{5}{*}{ 5. Distance from lineament (meter) } & $>300$ & 0.059 & 0.193 & 152,220 & 4711 & 0.32 \\
\hline & $300-600$ & & 0.114 & 134,775 & 4031 & 0.33 \\
\hline & $600-900$ & & 0.047 & 82,631 & 141 & 0.17 \\
\hline & $900-1200$ & & 0.024 & 38,470 & 80 & 0.21 \\
\hline & $1200<$ & & 0.016 & 58,079 & 105 & 0.18 \\
\hline \multirow[t]{5}{*}{ 6. Distance from River (m) } & 2000 & 0.051 & 0.012 & 62,935 & 163 & 0.25 \\
\hline & $1500-2000$ & & 0.038 & 83,911 & 773 & 1.07 \\
\hline & $1000-1500$ & & 0.076 & 104,889 & 2404 & 0.43 \\
\hline & $500-1000$ & & 0.114 & 92,302 & 1116 & 0.82 \\
\hline & 500 & & 0.152 & 75,520 & 6130 & 1.18 \\
\hline \multirow[t]{4}{*}{ 7. Soil type } & w-002 & 0.043 & 0.188 & 118,850 & 731 & 0.61 \\
\hline & w-004 & & 0.031 & 8141 & 1321 & 16.22 \\
\hline & w-006 & & 0.015 & 99,212 & 3548 & 3.57 \\
\hline & w-009 & & 0.125 & 193,354 & 2988 & 1.54 \\
\hline \multirow[t]{8}{*}{ 8. Land-use and land-cover } & River & 0.039 & 0.197 & 24,480 & 195 & 1.25 \\
\hline & Fellow land & & 0.172 & 48,895 & 1370 & 0.95 \\
\hline & Sandbank & & 0.147 & 120,714 & 1905 & 0.63 \\
\hline & Settlement & & 0.133 & 113,042 & 1140 & 0.79 \\
\hline & Cultivation land & & 0.073 & 57,301 & 855 & 0.67 \\
\hline & Plantation agriculture & & 0.049 & 33,535 & 660 & 0.51 \\
\hline & Open forest & & 0.024 & 23,405 & 1265 & 0.18 \\
\hline & Dense forest & & 0.012 & 18,535 & 723 & 0.26 \\
\hline
\end{tabular}


Table 6 (continued)

\begin{tabular}{|c|c|c|c|c|c|c|}
\hline \multirow[t]{2}{*}{ Main factor (layer sequence no.) } & \multirow[t]{2}{*}{ Subclass } & \multicolumn{2}{|c|}{ AHP method } & \multicolumn{3}{|c|}{ FR values of the landslide conditioning } \\
\hline & & $\begin{array}{l}\text { Consist- } \\
\text { ency Ratio } \\
\text { (CR) }\end{array}$ & Priority $\left(R_{i}\right)$ & $\begin{array}{l}\text { Number of } \\
\text { pixel in sub- } \\
\text { class }\end{array}$ & $\begin{array}{l}\text { Number of pixel } \\
\text { under landslide }\end{array}$ & Frequency ratio \\
\hline \multirow[t]{9}{*}{ 9. Aspect } & Flat & 0.033 & 0.002 & 147 & 18 & 0.08 \\
\hline & North & & 0.028 & 25,022 & 50 & 0.20 \\
\hline & North-east & & 0.002 & 58,824 & 395 & 0.67 \\
\hline & East & & 0.003 & 59,310 & 657 & 0.14 \\
\hline & South-east & & 0.041 & 68,039 & 599 & 1.10 \\
\hline & South & & 0.060 & 70,466 & 1348 & 1.91 \\
\hline & South-west & & 0.041 & 64,586 & 1454 & 2.25 \\
\hline & West & & 0.006 & 49,014 & 1449 & 2.95 \\
\hline & North-west & & 0.003 & 49,285 & 758 & 1.53 \\
\hline
\end{tabular}

forest (0.79); soil w-002 (0.061); sandbank (0.18); distance from lineament subclass 600-900 m (0.17); 900-1200 m (0.21); and more than $1200 \mathrm{~m}$ (0.18) (Table 6). BLR model shows that the all the factors have not equal role in making the area susceptible to landslide in Kurseong and its surrounding. Slope (0.028); altitude (0.338); rainfall (1.476); geological structure (0.119); settlement; fellow land; and cultivation land in LULC have a positive role in causing the $\mathrm{LS}$ as the coefficient value which has found in the BLRM is positive. On the other hand, FCFs like distance from the river (-0.005) and w-006 (soil type) distance from the lineaments have a negative relationship with the LS. According to the BLR, rainfall (4.37) is the most important determining factor for the landslide in this region (Table 7).

Applying the AHP method (Table 5), LSZ map was obtained. The higher value of the LSI indicates the higher probability of landslide and vice versa. The LSI has a minimum value of 1.08 and the highest value of 2.85 . The Kurseong range and its surrounding areas were divided into major 5 susceptibility regions according to the quintile method [57]: very low $16.63 \%$ of total area $63.25 \mathrm{~km}^{2}$, low $21.43 \%$ of total area $81.19 \mathrm{~km}^{2}$, moderate $88.65 \mathrm{~km}^{2}$, high $20.88 \%$ of total area $99.91 \mathrm{~km}^{2}$ and very high $17.75 \%$ of total area $71.08 \mathrm{~km}^{2}$ (Fig. 5a; Table 8).

Applying the FR model, an LSZ map was obtained. If the $\mathrm{LSI}$ value is very higher, it means a high probability of landslide; lower value means lower probability to the landslide. The LSI has a minimum value of 10.48 , and the highest value of 42.85 came in probability assessment. The Kurseong range and its surrounding were divided into major 5 susceptibility regions according to the quintile method [57]: very low, low, moderate, high and very high susceptibility classes cover $24.63 \%\left(93.63 \mathrm{~km}^{2}\right) ; 17.72 \%\left(71.19 \mathrm{~km}^{2}\right)$; $\left(33.09 \mathrm{~km}^{2}\right), 11.70 \%\left(44.50 \mathrm{~km}^{2}\right) ; 26.27 \%\left(99.91 \mathrm{~km}^{2}\right)$ and
$19.69 \%\left(71.08 \mathrm{~km}^{2}\right)$ areas of the study area, respectively (Fig. 5b; Table 8). Another single model BLR (Fig. 5c) was very high $13.23 \%\left(50.23 \mathrm{~km}^{2}\right)$; low $20.67 \%\left(78.61 \mathrm{~km}^{2}\right)$; and very low $30.48 \%\left(113.58 \mathrm{~km}^{2}\right)$ LS suspect region.

In ensemble AHP-FR, AHP-BLR and FR-BLR models, very low, high and very high susceptibility classes cover $18.92 \%\left(71.59 \mathrm{~km}^{2}\right), 20.68 \%\left(78.63 \mathrm{~km}^{2}\right)$ and $18.64 \%(71.31$ $\left.\mathrm{km}^{2}\right) ; 23.22 \%\left(88.31 \mathrm{~km}^{2}\right), 16.36 \%\left(62.21 \mathrm{~km}^{2}\right)$ and $17.43 \%$ $\left(66.29 \mathrm{~km}^{2}\right)$; and $22.72 \%\left(86.40 \mathrm{~km}^{2}\right), 21.47 \%\left(81.64 \mathrm{~km}^{2}\right)$ and $18.29 \%\left(69.56 \mathrm{~km}^{2}\right)$ of the study area, respectively (Fig. 5d-f).

\subsection{Models validation and comparison}

For measuring the prediction accuracy of landslide susceptibility maps induced by different methods, application of suitable methods is necessary. Among the different validation approaches, area under curve (AUC) of receiver operating characteristic (ROC) curve has been widely used in geographical community $[28,47]$. The ROC has been prepared by plotting the true positive (TP) against the false positive (FP) values at different threshold settings. ROC represents the true positive rate (TPR) and the false positive rate (FPR). The true positive rate (TPR) is called as the sensitivity, and false positive rate (FPR) is termed as specificity. The higher TPR denotes more accuracy, and higher FPR reflects error prediction of the models. ROC curves were used to decide the threshold value for the LSZ map $[17,19,56]$. The area under the curve (AUC) reflects the accuracy of the model $[19,46,59,66]$. The area under curve (AUC) values can be classified into five categories such as poor (0.5-0.6), average (0.6-0.7), good (0.7-0.8), very good $(0.8-0.9)$ and excellent $(0.9-1)[2,64,65]$. The 
Table 7 Coefficient of logistic regression model of landslide conditioning factors

\begin{tabular}{|c|c|c|c|c|c|c|c|c|}
\hline \multirow[t]{2}{*}{ Independence variable } & \multirow[t]{2}{*}{ B } & \multirow[t]{2}{*}{ SE } & \multirow[t]{2}{*}{ WaldChi } & \multirow[t]{2}{*}{$d f r$} & \multirow[t]{2}{*}{ Sig } & \multirow[t]{2}{*}{$\operatorname{Exp}(B)$} & \multicolumn{2}{|c|}{$95 \% \mathrm{Cl}$ for $\operatorname{Exp}(\mathrm{B})$} \\
\hline & & & & & & & Upper & Lower \\
\hline Slope & 0.028 & 0.003 & 13.401 & 1 & 0.002 & 1.028 & 1.980 & 0.970 \\
\hline Altitude & 0.334 & 0.167 & 0.398 & 1 & 0.039 & 1.397 & 1.477 & 1.131 \\
\hline Rainfall & 1.476 & 0.108 & 93.714 & 1 & 0.000 & 4.375 & 9.881 & 2.251 \\
\hline Distance from lineament & 0.001 & 0.007 & 5.013 & 1 & 0.023 & 1.001 & 1.02 & 0.98 \\
\hline \multicolumn{8}{|l|}{ Geology } & 0.998 \\
\hline Alluvial* & 1.194 & 0.334 & 11.224 & 1 & 0.005 & 3.300 & 3.141 & 2.981 \\
\hline Gneiss* & 1.445 & 0.530 & 7.842 & 1 & 0.006 & 4.242 & 4.328 & 3.924 \\
\hline States-schist* & 0.119 & 0.051 & 4.642 & 1 & 0.000 & 1.126 & 1.129 & 1.121 \\
\hline Limestone* & 1.114 & 0.402 & 6.987 & 1 & 0.005 & 3.047 & 3.659 & 2.489 \\
\hline Damuda* & 1.102 & 0.384 & 4.487 & 1 & 0.005 & 3.010 & 3.257 & 1.884 \\
\hline Distance from lineament & 0.001 & 0.007 & 5.013 & 1 & 0.023 & 1.001 & 1.02 & 0.98 \\
\hline Distance from river & -0.005 & 0.003 & 33.58 & 1 & 0.000 & 0.995 & 0.992 & 0.998 \\
\hline \multicolumn{9}{|l|}{ Soil type } \\
\hline w-002 & 0.084 & 0.012 & 14.068 & 1 & 0.082 & 1.088 & 1.224 & 0.768 \\
\hline w-004 & 0.091 & 0.013 & 25.625 & 1 & 0.002 & 1.095 & 1.909 & 0.0941 \\
\hline w-006 & 0.078 & 0.012 & 43.609 & 1 & 0.000 & 1.081 & 1.671 & 0.932 \\
\hline w-009 & 0.048 & 0.007 & 6.289 & 1 & 0.000 & 1.049 & 1.835 & 0.914 \\
\hline \multicolumn{9}{|l|}{ LULC } \\
\hline Settlement* & 0.122 & 0.061 & 6.152 & 1 & 0.000 & 1.130 & 2.195 & 1.113 \\
\hline Fellow land* & 2.478 & 0.065 & 7.125 & 1 & 0.000 & 11.917 & 12.651 & 4.766 \\
\hline Open forest* & 3.412 & 0.039 & 7.048 & 1 & 0.000 & 30.326 & 31.102 & 5.292 \\
\hline Dense forest* & -1.744 & 0.105 & 2.781 & 1 & 0.732 & 2.175 & 2.845 & 1.332 \\
\hline Cultivation land* & 1.062 & 0.435 & 18.306 & 1 & 0.000 & 2.892 & 2.985 & 2.735 \\
\hline \multicolumn{9}{|l|}{ Aspect } \\
\hline North* & -0.179 & 0.025 & 50.35 & 1 & 0.010 & 0.836 & 0.849 & 0.821 \\
\hline North-east* & 0.348 & 0.004 & 70.49 & 1 & 0.000 & 1.416 & 1.728 & 1.684 \\
\hline East* $^{*}$ & -0.447 & 0.007 & 14.31 & 1 & 0.000 & 0.640 & 0.704 & 0.614 \\
\hline South-east* & 0.531 & 0.003 & 29.64 & 1 & 0.010 & 1.701 & 2.571 & 1.561 \\
\hline South* & -0.632 & 0.031 & 11.94 & 1 & 0.000 & 0.532 & 0.603 & 0.503 \\
\hline South-west* & -1.185 & 0.013 & 48.17 & 1 & 0.000 & 0.306 & 0.564 & 0.298 \\
\hline West $^{*}$ & -1.32 & 0.037 & 14.45 & 1 & 0.000 & 0.267 & 0.327 & 0.101 \\
\hline North-west* & -2.199 & 0.031 & 49.45 & 1 & 0.030 & 0.111 & 0.343 & 0.049 \\
\hline Intercept & 0.221 & 0.045 & 22.709 & 1 & 0.019 & 1.247 & & \\
\hline
\end{tabular}

$\mathrm{B}=$ Calculated coefficient value; $\mathrm{SE}=$ standard error of estimate; WaldChi=Wald Chi-square values; $d f r=$ degree of freedom; Sig. = significance. ${ }^{*}$ Categorical data intensity of the accuracy of the model has been categorized after Pradhan et al. [14].

The perfect model demonstrates a curve that has the largest area under curve (AUC). A perfect model concludes an AUC value nearest to 1.0 , whereas a value close to 0.5 indicates the erroneousness of the model $[13,45,65,66]$. In the study, the ROC curve was produced by imprint $y$-axis TPR against FPR at the $x$-axis with a fixed threshold or cutoff value (Fig. 6). The constructed LSZ map was matched up to recognize landslide locations through ROC curve. To verify the accuracy rate of LSZ maps, 66 of the 221 landslide points were used (Table 8 ). The diagram (Fig. 6) is showing the AUC values are $78.86 \%$ in $A H P, 80.22 \%$ in $F R$, $80.67 \%$ in BLRM, $83.44 \%$ in AHP-FR, 84.39\% in AHP-BLR and $84.73 \%$ in FR-BLR models. All the models revealed a very good accuracy in mapping the landslide susceptibility (Fig. 6). Another accuracy process, kappa statistics, showed that overall accuracy is 0.789 in AHP, 0.842 in FR, 0.799 in the BLR, AHP-FR 0.837, AHP-BLR 0.856 and 0.868 in FR-BLR models for the final output maps (Table 9). The ROC and kappa statistics both results were showed FR-BLR ensemble model giving better output and AHP model giving comparatively low accuracy in mapping the susceptibility to landslide in Kurseong of Darjeeling Himalaya. 

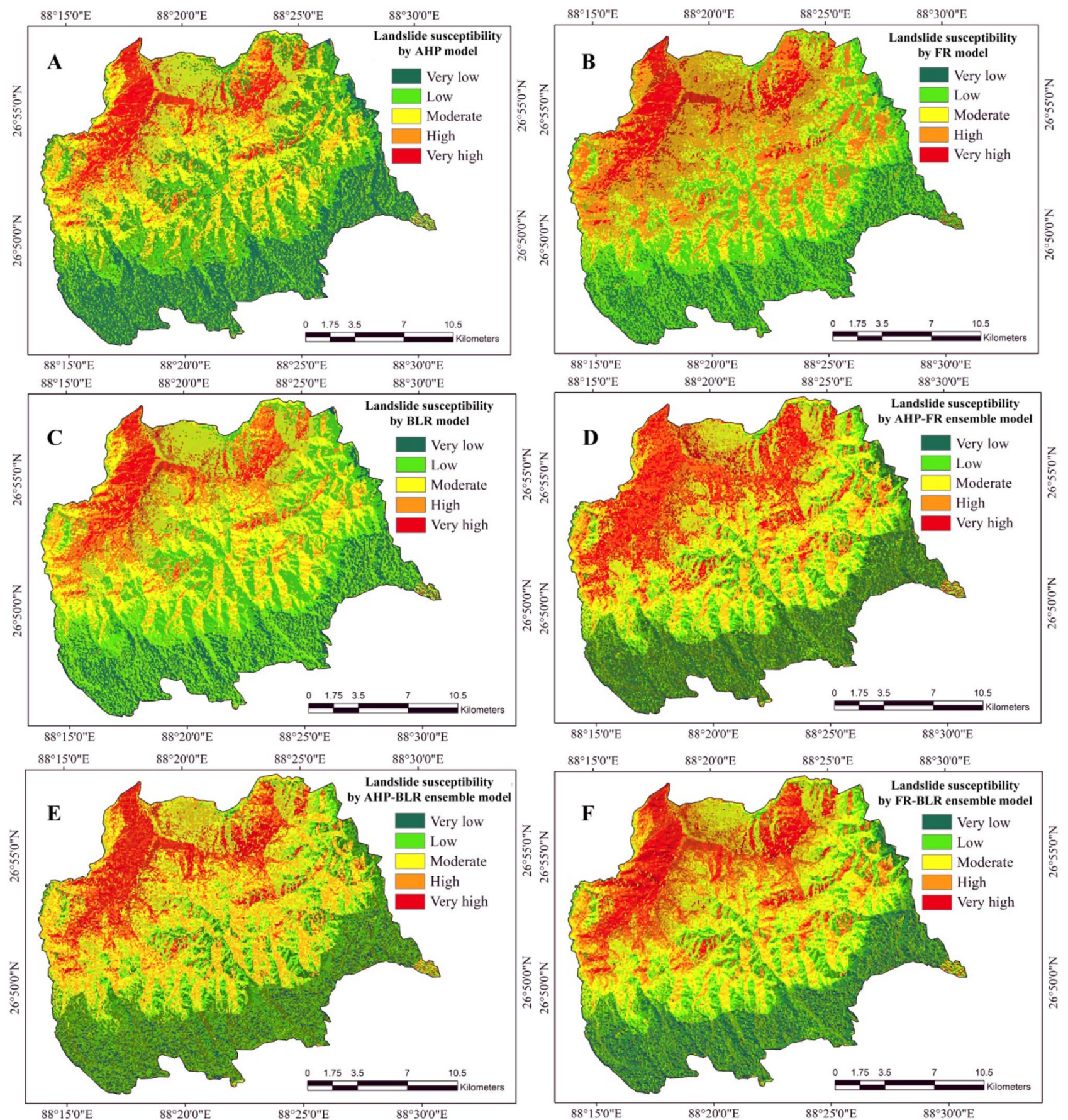

Fig. 5 Landslide susceptibility maps prepared by a AHP method and statistical prediction techniques, b FR model, c BLR model, d AHP-FR model, e AHP-BLR model and f FR-BLR model 


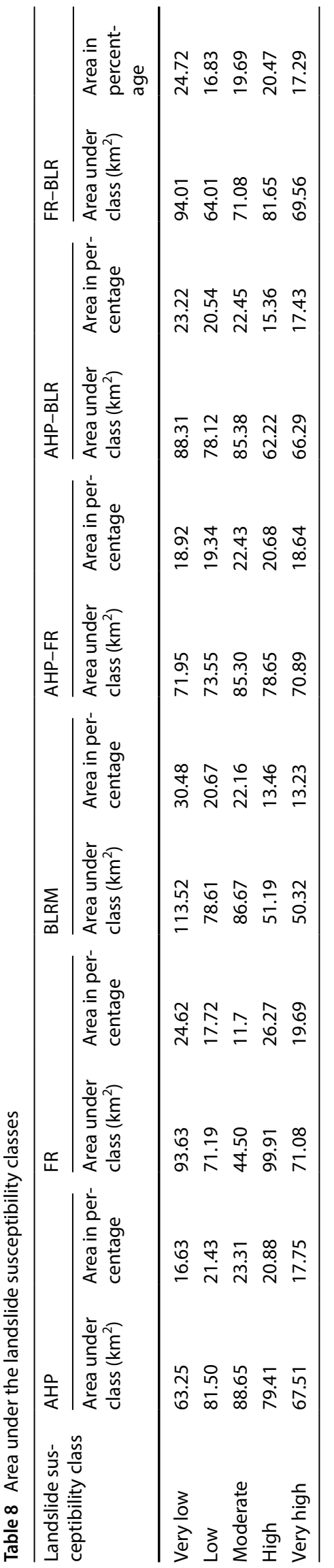

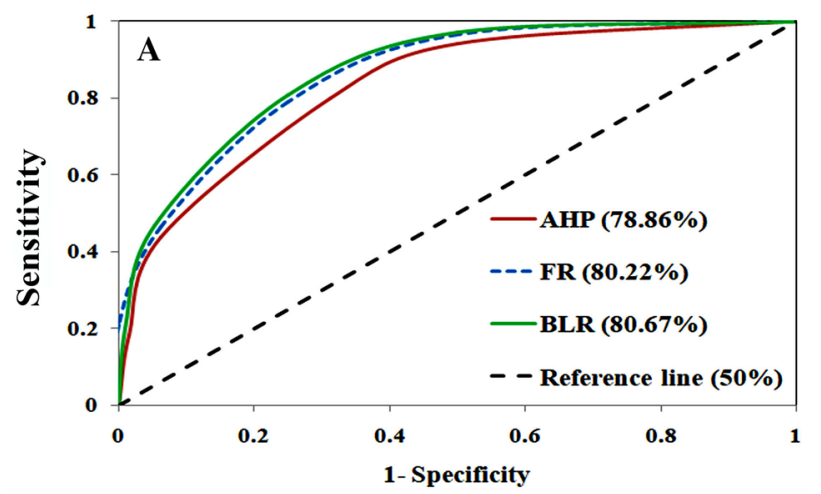

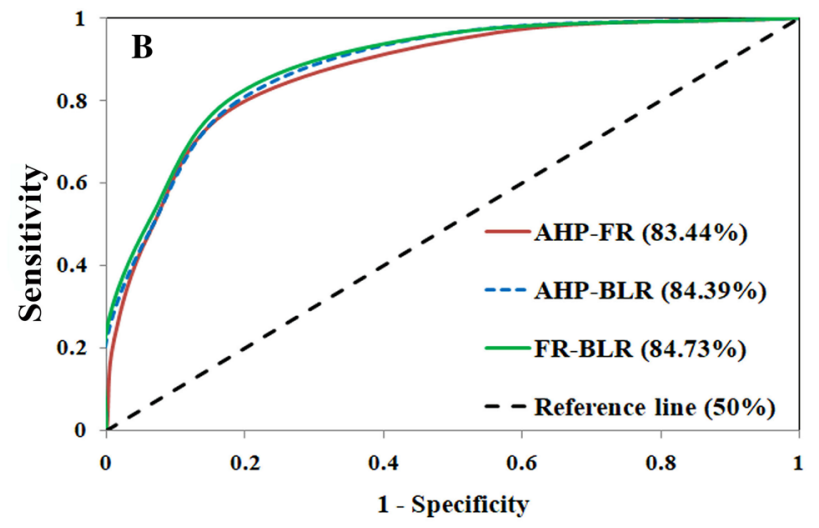

Fig. 6 ROC curve for the assessment of susceptibility maps prepared for a AHP $(83.58 \%)$, FR $(86.82 \%)$, BLRM $(85.17 \%)$; b AHP-FR (85.34\%), AHP-BLR (87.32\%) and FR-BLR (88.73\%) models

\section{Discussion}

Landslide is a complex phenomenon on account of multiple variables influence in its occurrence. Improving the performance of models of LS susceptibility has still drawn enormous attention from the research community for proper mapping. The application of remote sensing and GIS can be useful in the study of hazard management due to their high accuracy and speed where accuracy and time are two vital aspects of landslide modeling $[1,34,67,68]$. Factor selection is also a significant concern for making the model more effective and precise. Different causes lead to the occurrence of landslides where some are significant and others are minor contributory factors $[34,61]$.

Different methodologies were examined from the viewpoints of effectiveness and reliability to prepare LS susceptibility maps. This present study attempted to assess the proficiency of various methods such as knowledgedriven AHP, probabilistic FR and BLR models and ensemble models AHP-FR, AHP-BLR and FR-BLR to assess the LS susceptibility of Kurseong region of the Himalaya, India. The employ of ensemble methods to generate high accuracy mapping $[68,69]$ is considered an important step in this 


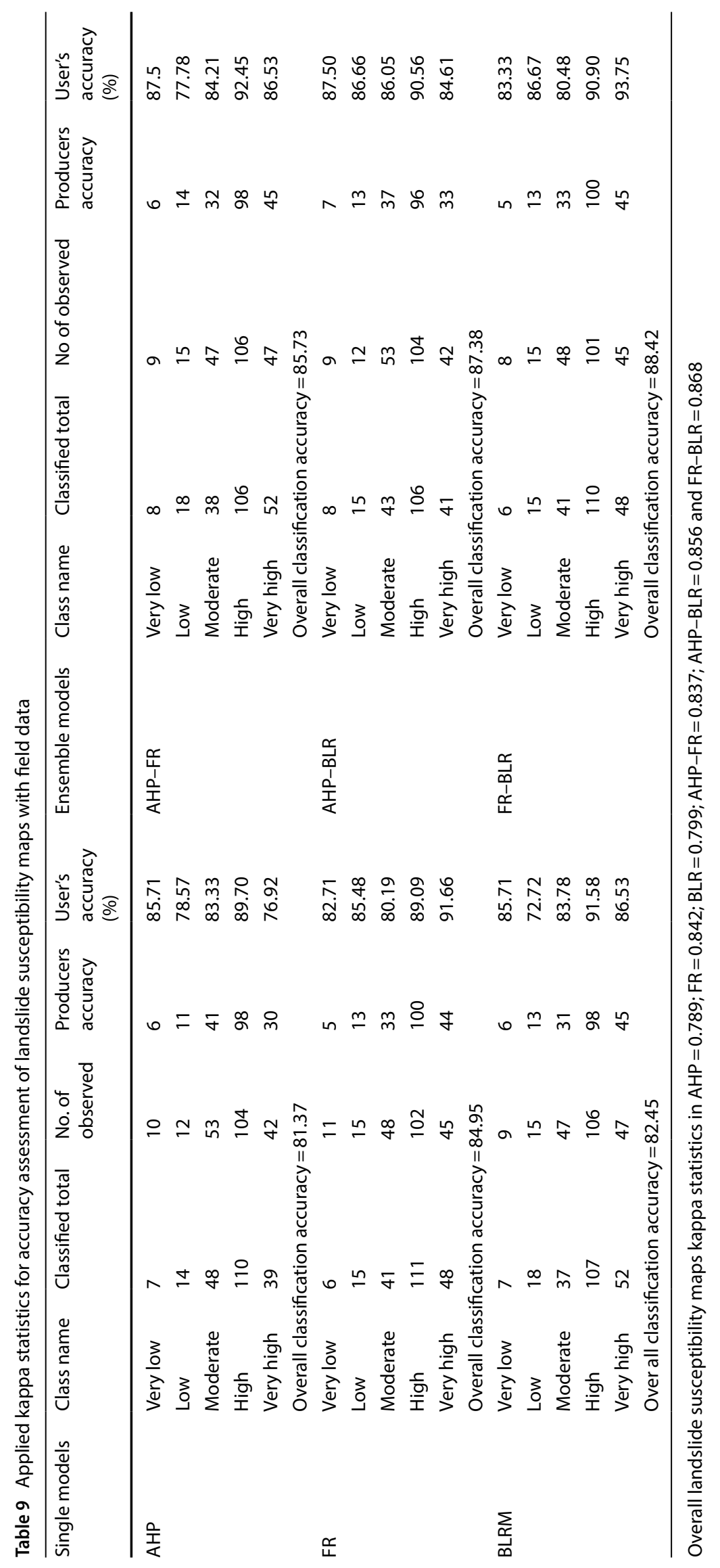


regard. This Kurseong is chosen as a case study because of the high frequency of LS in eastern Himalaya and high sensitivity of this area in terms of population, concentration, tea garden and agricultural land.

At the first and second steps, LS inventory map (221 LS locations) was made and randomly divided into two subsets for testing and training (70:30), respectively, and after that, LS-conditioning factors were prepared after multi-collinearity test. Afterward, these factors were used to correlate LS with the each class of conditioning factors and then evaluated the susceptibility to LS by AHP, FR, BLR, AHP-FR, AHP-BLR and FR-BLR models. The LSMs were constructed and classified into five categories in order to produce the susceptibility map. The success rate and prediction rate curves were used to determine efficiencies and compare the results of LSMs. The landslide susceptible maps both single model and ensemble model have provided better result than the previous works done by the different researchers in the Himalayan region $[5,8$, $17,27,29,33,46]$. In addition, validation results indicated the better performance of FR-BLR ensemble model with a prediction rate of $84.76 \%$ compared with $A H P, F R, B L R$, the ensemble of AHP-FR and AHP-BLR models having the AUC values of $78.86 \%, 80.67 \%, 83.44 \%$ and $84.39 \%$ respectively. A different accuracy process, kappa statistics, confirmed that overall accuracy is 0.789 in AHP, 0.842 in FR, 0.799 in the BLR, AHP-FR 0.837, AHP-BLR 0.856 and 0.868 in FR-BLR models for the final output maps.

It is shown in Tables 5 and 8 that the Damuda, limestone geological structure with slope above $15^{\circ}$ and altitude above $1500 \mathrm{~m}$ are extremely vulnerable to landslides. Areas closer to the lineament and river are highly susceptible to landslides. Soil type w-004 (Loamy-skeletal, Typic Udorthents and Loamy-skeletal, Typical Haplumbbrepts) also plays a crucial role in triggering landslides. Sandy clay with the largest frequency ratio was identified as the most susceptible type. Intense commercial agriculture is done in this particular soil type by small terraces. Most of the settlements are located in the moderately susceptible areas. Site-specific slope control is necessary to check and mitigate landslide phenomena in the Kurseong range and its surrounding region. The LS maintenance could involve armoring the drain along the junction between the road and the hill slope, building a retaining wall, wall and trap water drain, controlling subsurface water, installation of fern vegetation, strict and constant surveillance along $\mathrm{NH}$ 55 and road diversion to prevent high landslide occurrence. The failure of unstable slopes in hazardous areas, in addition to fatalities and economic damage, has devastating social and environmental effects. Identification of vulnerable landslide areas is an important source for local authorities and decision makers.

\section{Conclusion}

The LSZ maps of Kurseong subdivision of Himalaya were produced using one knowledge-driven method, i.e., AHP method, two probabilistic methods, i.e., FR and BLR and their ensemble, i.e., AHP-FR, AHP-BLR and FR-BLR. Major 9 landslide-conditioning factors have been considered for the generation of landslide susceptibility maps using GIS. The numerical weights have been assigned by AHP, FR and $B L R$ to each subclass of every factor, after ensemble approach applied for AHP-FR, AHP-BLR and FR-BLR modeling landslide susceptibility. LSZ maps study areas have been classified into five zones, such as very high, high, medium, low and very low. The AHP-based LSZ map shows that large portion of the study area (38.63\%) falls in high and very high LS susceptibility due to the prevalence of very steep slopes, high altitude, rainfall and distance from the river. On the other hand, FR model-based map showed $45.96 \%$ and BLRM showed $26.69 \%$ of the total areas fall in high and very high LSZ. But their ensembles AHP-FR map showed $39.32 \%$, AHP-BLR map showed $32.79 \%$, and FR-BLR showed $37.76 \%$ of total area under very high and high LSZ. The low LSZ is safe for construction and needs some geotechnical investigation before any construction. The outcome of the LSZ mapping was verified applying the ROC curve and kappa statistics. The ROC curves are showing $78.86 \%$ (AHP), 80.22\% (FR), 80.67\% (BLR), 83.44\% (AHP-FR), 84.39\% (AHP-BLR) and $84.76 \%$ (FR-BLR) accuracy of models, respectively. Similarly, kappa coefficient values also show the accurateness of the produced landslide susceptible maps. Therefore, the LSZ maps can be used for LULC planning and future construction in this mountain region. The LSZ map can be efficiently used for ensuring further developmental activities. In addition, the probability map of the region will provide enough information about current and future possibility of landslides to common people, engineers and planners.

Acknowledgements Authors would like to thank the inhabitants of Basin because they have helped a lot during our field visit. Authors would like to thank the anonymous reviewers and editor for their valuable suggestions to improve the manuscript. At last, authors would like to acknowledge all of the agencies and individuals specially, Survey of India (SOI), Geological Survey of India (GSI) and USGS for providing the maps and data required for the study.

Authors' Contributions All the authors wrote the manuscript and developed the research methodology. All the authors also read and approved the final manuscript.

Funding No funding was received for this work. 


\section{Compliance with ethical standards}

Conflict of interest The authors declare that they have no competing interests.

\section{References}

1. Saha S, Saha A, Hembram TK, Pradhan B, Alamri AM (2020) Evaluating the performance of individual and novel ensemble of machine learning and statistical models for landslide susceptibility assessment at Rudraprayag District of Garhwal Himalaya. Appl Sci 10(11):3772

2. Basu T, Das A, Pal S (2020) Application of geographically weighted principal component analysis and fuzzy approach for unsupervised landslide susceptibility mapping on Gish River Basin, India. Geocarto Int. https://doi.org/10.1080/10106 049.2020 .1778105

3. Igwe O, Una CO (2019) Landslide impacts and management in Nanka area. Southeast Nigeria Geoenviron Disasters 6(1):5

4. Basharat M, Shah HR, Hameed N (2016) Landslide susceptibility mapping using GIS and weighted overlay method: a case study from NW Himalayas, Pakistan. Arab J Geosci 9:1-19. https://doi. org/10.1007/s12517-016-2308-y

5. Saha A, Saha S (2020) (2020) Application of statistical probabilistic methods in landslide susceptibility assessment in Kurseong and its surrounding area of Darjeeling Himalayan, India: RS-GIS approach. Environ Dev Sustain. https://doi.org/10.1007/s1066 8-020-00783-1

6. Bamisaiye OA (2019) Landslide in parts of south-western Nigeria. SN Appl Sci 1(7):745

7. Pal SC, Chowdhuri I (2019) GIS-based spatial prediction of landslide susceptibility using frequency ratio model of Lachung River basin, North Sikkim, India. SN Appl Sci 1(5):416

8. Dimri S, Lakhera RC, Sati S (2007) Fuzzy-based method for landslide hazard assessment in active seismic zone of Himalaya. Landslides 4(2):101

9. Lee S, Sambath T (2006) Landslide susceptibility mapping in the Damreiromal area, Cambodia using frequency ratio and logistic regression models. J Environ Geol 50:847-855. https://doi. org/10.1155/2017/3730913

10. Kouli M, Loupasakis C, Soupios P, Vallianatos F (2010) Landslide hazard zonation in high-risk area of Rethymno Prefecture, Crete Island, Greece. Nat Hazards 52:599-621. https:// doi.org/10.1007/s11069-009-9403-2

11. Sakkas G, Misailidis I, Sakellariou N, Kouskouna V, Kaviris G (2016) Modeling landslide susceptibility in Greece: a weighted linear combination approach using analytic hierarchical process, validated with spatial and statistical analysis. Nat Hazards 84(3):1873-1904

12. Lee S, Pradhan B (2007) Landslide hazard mapping at Selangor Malaysia using frequency ratio and logistic regression models. Landslides 4:33-41. https://doi.org/10.1007/s 1034 6-006-0047-y

13. Raghuvanshi TK, Ibrahim J, Ayalew D (2014) Slope stability susceptibility evaluation parameter (SSEP) rating schemean approach for landslide hazard zonation. J Afr Earth Sci 99:595-612

14. Pradhan B, Lee $S$ (2010) Landslide susceptibility assessment and factor effect analysis: back propagation artificial neural networks and their comparison with frequency ratio and bivariate logistic regression modeling. Environ Model Softw 25:747-759. https://doi.org/10.1088/1755-1315/20/1/012031
15. Saaty $T$ (1990) The analytic hierarchy process: planning, priority setting, resource allocation. RWS Publications, Pittsburgh

16. Wu CH, Chen SC (2009) Determining landslide susceptibility in Central Taiwan from rainfall and six site factors using the analytical hierarchy process method. Geomorphology 112(3-4):190-204

17. Kayastha P, Dhital MR, De Smedt F (2013) Application of the analytical hierarchy process (AHP) for landslide susceptibility mapping: a case study from the Tinau watershed, west Nepal. Comput Geosci 52:398-408

18. Sharma LP, Patel N, Debnath $P$ (2012) Assessing landslide vulnerability from soil characteristics a GIS-based analysis. Arab J Geosci 5:789. https://doi.org/10.1007/s12517-010-0272-5

19. Park S, Choi C, Kim B, Kim J (2013) Landslide susceptibility mapping using frequency ratio, analytic hierarchy process, logistic regression, and artificial neural network methods at the Inje area, Korea. Environ Earth Sci 68(5):1443-1464. https ://doi.org/10.1007/s12665-012-1842-5

20. Shit PK, Bhunia GS, Maiti R (2016) (2016) Potential landslide susceptibility mapping using weighted overlay model (WOM) model. Earth Syst Environ 2:21. https://doi.org/10.1007/s4080 8-016-0078-x

21. Nithya ES, Prasanna RP (2010) An integrated approach with GIS and remote sensing technique for landslide zonation. Int J Geom Geosci 1:66-75

22. Nguyen $\mathrm{H}$, Mehrabi $\mathrm{M}$, Kalantar $\mathrm{B}$, Moayedi $\mathrm{H}$, Abdullahi MAM (2019) Potential of hybrid evolutionary approaches for assessment of geo-hazard landslide susceptibility mapping. Geomatics, Natural Hazards and Risk 10(1):1667-1693

23. Van Dao D, Jaafari A, Bayat M, Mafi-Gholami D, Qi C, Moayedi $\mathrm{H}$ et al (2020) A spatially explicit deep learning neural network model for the prediction of landslide susceptibility. CATENA 188:104451

24. Xi W, Li G, Moayedi H, Nguyen H (2019) A particle-based optimization of artificial neural network for earthquake-induced landslide assessment in Ludian county, China. Geom Nat Hazards Risk 10(1):1750-1771

25. Moayedi H, Huat BB, Ali TAM, Asadi A, Moayedi F, Mokhberi $M$ (2011) Preventing landslides in times of rainfall: case study and FEM analyses. Disaster Prevent Manag Int J 20:115-124

26. Moayedi H, Mehrabi M, Kalantar B, Abdullahi-Mu'azu M, Rashid AS, Foong LK, Nguyen H (2019) Novel hybrids of adaptive neuro-fuzzy inference system (ANFIS) with several metaheuristic algorithms for spatial susceptibility assessment of seismic-induced landslide. Geom Nat Hazards Risk 10(1):1879-1911

27. Sarkar S, Kanungo DP, Mehrotra GS (1995) Landslide hazard zonation: a case study in Garhwal Himalaya, India. Mt Res Dev 15:301-309

28. Roy J, Saha S (2019) Landslide susceptibility mapping using knowledge driven statistical models in Darjeeling District, West Bengal, India. Geoenviron Disasters 6(1):11

29. Lee S, Pradhan B (2007) Landslide hazard mapping at Selangor, Malaysia using frequency ratio and logistic regression models. Landslides 4(1):33-41

30. Ayalew L, Yamagishi H (2005) The application of GIS-based logistic regression for landslide susceptibility mapping in the Kakuda-Yahiko Mountains, Central Japan. Geomorphology 65(1-2):15-31

31. Zhao Y, Wang R, Jiang Y, Liu H, Wei Z (2019) GIS-based logistic regression for rainfall-induced landslide susceptibility mapping under different grid sizes in Yueqing South-eastern China. Eng Geol 259:105147

32. Regmi AD, Devkota KC, Yoshida K, Pradhan B, Pourghasemi HR, Kumamoto T, Akgun A (2014) Application of frequency ratio, statistical index, and weights-of-evidence models and their 
comparison in landslide susceptibility mapping in Central Nepal Himalaya. Arab J Geosci 7(2):725-742

33. Mandal S, Saha A (2018) Support vector machines for monitoring land use dynamicity and temporal variation of land surface temperature in Kurseong and surrounding of Darjeeling Himalaya. Model Earth Syst Environ 4:659-672. https://doi. org/10.1007/s40808-018-0430-4

34. Saha A, Saha S (2020) Comparing the efficiency of weight of evidence, support vector machine and their ensemble approaches in landslide susceptibility modelling: a study on Kurseong region of Darjeeling Himalaya, India. Remote Sens Appl Soc Environ. https://doi.org/10.1016/j.rsase.2020.10032 3

35. Goetz JN, Brenning A, Petschko H, Leopold P (2015) Evaluating machine learning and statistical prediction techniques for landslide susceptibility modeling. Comput Geosci 81:1-11

36. Steger S, Brenning A, Bell R, Glade T (2017) The influence of systematically incomplete shallow landslide inventories on statistical susceptibility models and suggestions for improvements. Landslides 14(5):1767-1781

37. Wang $Y$, Fang $Z$, Wang $M$, Peng L, Hong H (2020) Comparative study of landslide susceptibility mapping with different recurrent neural networks. Comput Geosci 138:104445

38. Liu CC, Ko MH, Wen HL, Fu KL, Chang ST (2019) Instability Index Derived from a Landslide Inventory for Watershed Stability Assessment and Mapping. ISPRS Int J Geo-Inf 8(3):145

39. Saaty $T$ (2008) Decision making with the analytic hierarchy process. Int J Serv Sci 1:23

40. Rezaei-Moghaddam K, Karami E (2008) A multiple criteria evaluation of sustainable agricultural development models using AHP. Environ Dev Sustain 10:407-426

41. Bhushan N, Rai K (2004) Strategic decision making: applying the analytic hierarchy process. Springer, New York, p. 172. ISBN: 978-1-85233-864-0

42. Şener Ş, Şener E, Nas B, Karagüzel R (2010) Combining AHP with GIS for landfill site selection: a case study in the Lake Beyşehir catchment area (Konya, Turkey). Waste Manage 30(11):2037-2046

43. Lee S, Pradhan B (2006) Probabilistic landslide hazards and risk mapping on Penang Island, Malaysia. J Earth Syst Sci 115:661. https://doi.org/10.1007/s12040-006-0004-0

44. Hong H, Pourghasemi HR, Pourtaghi ZS (2016) Landslide susceptibility assessment in Lianhua County (China): a comparison between a random forest data mining technique and bivariate and multivariate statistical models. Geomorphology 259:105-118

45. Regmi AD, Yoshida K, Dhital MR et al (2013) Effect of rock weathering, clay mineralogy, and geological structures in the formation of large landslide, a case study from Dumre Besei landslide Lesser Himalaya. Landslides 10:1. https://doi.org/10.1007/s1034 6-011-0311-7

46. Poudyal CP, Chang C, Oh HJ, Lee S (2010) Landslide susceptibility maps comparing frequency ratio and artificial neural networks: a case study from the Nepal-Himalaya. Environ Earth Sci 61(5):1049-1064

47. Lin L, Lin Q, Wang Y (2017) Landslide susceptibility mapping on a global scale using the method of logistic regression. Nat Hazards Earth Syst Sci 17(8):1411-1424

48. Schlögel R, Marchesini I, Alvioli M, Reichenbach P, Rossi M, Malet JP (2018) Optimizing landslide susceptibility zonation: effects of DEM spatial resolution and slope unit delineation on logistic regression models. Geomorphology 301:10-20

49. Khosravi K, Nohani E, Maroufinia E, Pourghasemi HR (2016) A GIS-based flood susceptibility assessment and its mapping in
Iran: a comparison between frequency ratio and weights-ofevidence bivariate statistical models with multi-criteria decision-making technique. Nat Hazards 83(2):947-987. https:// doi.org/10.1007/s11069-016-2357-2

50. Althuwaynee OF, Pradhan B, Park HJ, Lee JH (2014) A novel ensemble bivariate statistical evidential belief function with knowledge-based analytical hierarchy process and multivariate statistical logistic regression for landslide susceptibility mapping. CATENA 114:21-36

51. Shafapour-Tehrany $M$, Shabani $F$, Neamah-Jebur $M$, Hong $H$, Chen W, Xie X (2017) GIS-based spatial prediction of flood prone areas using standalone frequency ratio, logistic regression, weight of evidence and their ensemble techniques. Geom Nat Hazards Risk 8(2):1538-1561. https://doi.org/10.1080/19475 705.2017.1362038

52. Thanh LN, De Smedt F (2012) Application of an analytical hierarchical process approach for landslide susceptibility mapping in A Luoi district, Thua Thien Hue Province, Vietnam. Environ Earth Sci 66:1739-1752. https://doi.org/10.1007/s12665-011-1397-x

53. Bai S, Wang J, Thiebes B et al (2014) Analysis of the relationship of landslide occurrence with rainfall: a case study of Wudu County China. Arab J Geosci 7:1277. https://doi.org/10.1007/ s12517-013-0939-9

54. Meziani B, Machane D, Bendaoud A et al (2017) Erratum to: Geotechnical and geophysical characterization of the Bouira-Algiers Highway (Ain Turck, Algeria) landslide. Arab J Geosci 10:147. https://doi.org/10.1007/s12517-017-2953-9

55. Rostami Z, Al-modaresi S, Fathizad H (2016) Landslide susceptibility mapping by using fuzzy logic: a case study of Chamgardalan catchment, Ilam Iran. Arab J Geosci 9:685. https://doi. org/10.1007/s12517-016-2720-3

56. Howard AD (1997) Badland morphology and evolution: an interpretation using a simulation model. Earth Surf Process Landf 22:211-227

57. Swets JA (1988) Measuring the accuracy of diagnostic systems. Science 240:1285-1293

58. Gariano SL, Sarkar R, Dikshit A, Dorji K, Brunetti MT, Peruccacci S, Melillo M (2019) Automatic calculation of rainfall thresholds for landslide occurrence in Chukha Dzongkhag, Bhutan. Bull Eng Geol Env 78(6):4325-4332

59. Petley D (2012) Global patterns of loss of life from landslides. Geology 40(10):927-930

60. ALSIoli, M., \& Baum, R. L. (2016) Parallelization of the TRIGRS model for rainfall-induced landslides using the message passing interface. Environ Model Softw 81:122-135

61. Brenning, A. (2012). Spatial cross-validation and bootstrap for the assessment of prediction rules in remote sensing: The $R$ package sperrorest. In: IEEE international geoscience and remote sensing symposium, pp 5372-5375

62. Hong H, Liu J, Bui DT, Pradhan B, Acharya TD, Pham BT et al (2018) Landslide susceptibility mapping using J48 Decision Tree with AdaBoost, Bagging and Rotation Forest ensembles in the Guangchang area (China). CATENA 163:399-413

63. Hong H, Miao Y, Liu J, Zhu AX (2019) Exploring the effects of the design and quantity of absence data on the performance of random forest-based landslide susceptibility mapping. CATENA 176:45-64

64. Rahmati O, Samani AN, Mahdavi M, Pourghasemi HR, Zeinivand $\mathrm{H}$ (2015) Groundwater potential mapping at Kurdistan region of Iran using analytic hierarchy process and GIS. Arab J Geosci 8(9):7059-7071. https://doi.org/10.1007/s12517-014-1668-4

65. Pourghasemi HR, Moradi HR, Aghda SF (2013) Landslide susceptibility mapping by binary logistic regression, analytical hierarchy process, and statistical index models and assessment 
of their performances. Nat Hazards 69(1):749-779. https://doi. org/10.1007/s11069-013-0728-5

66. Roy J, Saha S, Arabameri A, Blaschke T, Bui DT (2019) A Novel Ensemble Approach for Landslide Susceptibility Mapping (LSM) in Darjeeling and Kalimpong Districts, West Bengal, India. Remote Sensing 11(23):2866. https://doi.org/10.3390/rs112 32866

67. Yesilnacar EK (2005) The application of computational intelligence to landslide susceptibility mapping in Turkey. Ph. D Thesis Department of Geomatics the University Of Melbourne, p 423

68. Sun X, Chen J, Han X, Bao Y, Zhan J, Peng W (2020) Application of a GIS-based slope unit method for landslide susceptibility mapping along the rapidly uplifting section of the upper Jinsha River, South-Western China. Bull Eng Geol Env 79(1):533-549

69. Pham BT, Van Phong T, Nguyen-Thoi T, Trinh PT, Tran QC, Ho LS, et al (2020) GIS-Based Ensemble Soft Computing Models for Landslide Susceptibility Mapping. Adv Space Res

70. Pham BT, Jaafari A, Prakash I, Bui DT (2019) A novel hybrid intelligent model of support vector machines and the MultiBoost ensemble for landslide susceptibility modeling. Bull Eng Geol Env 78(4):2865-2886

Publisher's Note Springer Nature remains neutral with regard to jurisdictional claims in published maps and institutional affiliations. 